\title{
Transient tachypnoea of the newborn: two distinct clinical entities?
}

\author{
HENRY L HALLIDAY, GARTH McCLURE, AND MARK McC REID
}

Royal Maternity Hospital, Belfast

SUMmaRY Twenty-five infants with transient tachypnoea of the newborn (TTN) were examined by serial echocardiography during the first 4 days of life. The infants could be divided clinically into two groups: group $1(\mathrm{n}=19)$ babies with mild classical TTN requiring $<40 \%$ oxygen, and group 2 $(n=6)$ babies with severe TTN needing $>60 \%$ oxygen. Apart from amount of oxygen these two groups differed in that those with severe TTN had lower Apgar scores and arterial pH soon after birth. Echocardiography showed that the babies with classical TTN had increased left ventricular pre-ejection period to ejection time ratios (LPEP/LVET) during the first day of life. Initial LPEP/ LVET ratio correlated with duration of treatment with oxygen. The babies with severe TTN had increased LPEP/LVET and right ventricular pre-ejection period to ejection time ratios (RPEP/ RVET) during the first 3 days of life. There was no correlation between these systolic time intervals and duration of oxygen treatment. These findings suggest that there may be two distinct types of TTN: a mild or classical type resulting from mild left ventricular failure, and a severe type associated with generalised myocardial failure, pulmonary hypertension, and right-to-left shunting.

Transient tachypnoea of the newborn (TTN) is generally thought to be a benign self-limiting disease. The cause is believed to be delayed resorption of lung fluid. ${ }^{1}$ The clinical condition is characterised by tachypnoea with little evidence of respiratory distress. Chest radiographs show mild cardiomegaly, increased vascular markings, fluid in the horizontal fissure, and over-inflation of the lungs. ${ }^{2}$

In most instances the clinical condition is benign with infants requiring $<40 \%$ oxygen for 2 or 3 days. ${ }^{1-3}$ More recently however, some infants with TTN have been reported with severe symptoms and profound hypoxaemia resulting in the need for cardiac catherisation ${ }^{4}$ and mechanical ventilation. ${ }^{5}$ We have studied echocardiographically 25 infants with TTN in order to measure myocardial contractility and pulmonary vascular resistance. These studies suggest that there may be two distinct types of TTN which we have termed classical or benign, and severe.

\section{Patients and methods}

Nineteen newborn infants with classical, clinical, and radiological evidence of TTN were studied. ${ }^{2}$ The criteria for diagnosis were raised respiratory rate ( $>60$ breaths a minute) and radiographic findings as described above. ${ }^{2}$ In these infants oxygen require- ments were low and no baby needed more than $40 \%$ oxygen to maintain normal arterial oxygen tensions (Table). Ten infants were term and 9 were preterm. The infants were studied echocardiographically at

Table Clinical features of the infants with TTN

\begin{tabular}{|c|c|c|}
\hline & $\begin{array}{l}\text { Classical } \\
(n=19)\end{array}$ & $\begin{array}{l}\text { Severe } \\
(n=6)\end{array}$ \\
\hline \multicolumn{3}{|l|}{ Gestational age } \\
\hline Birthweight (kg) & $2 \cdot 70$ & $3 \cdot 26$ \\
\hline $\operatorname{Sex}(M: F)$ & $12: 7$ & $4: 2$ \\
\hline \multicolumn{3}{|l|}{ Apgar scores } \\
\hline $\begin{array}{l}\text { (1 and } 5 \text { minutes }) \\
\text { Respiratory } \mathrm{rate} / \mathrm{min}\end{array}$ & Respiratory rate/min & $4 \cdot 5$ and 7 \\
\hline at 12 hours & 72 & 68 \\
\hline Chest $x$-ray film & $\begin{array}{l}\text { Hyperinflation, } \\
\text { increased pulmonary } \\
\text { vascularity, and } \\
\text { fluid in horizontal } \\
\text { fissure }\end{array}$ & $\begin{array}{l}\text { Hyperinflation, } \\
\text { increased pulmonary } \\
\text { vascularity, and } \\
\text { fluid in horizontal } \\
\text { fissure }\end{array}$ \\
\hline Haematocrit (\%) & 58 & 62 \\
\hline \multicolumn{3}{|l|}{ Fluids in first 24 hours } \\
\hline$(\mathrm{ml} / \mathrm{kg})$ & 66 & 64 \\
\hline $\begin{array}{l}\text { Mean } \mathrm{F}_{1} \mathrm{O}_{2} \text { at } 24 \text { hours } \\
\text { pH on admission }\end{array}$ & $\begin{array}{l}0 \cdot 32 \\
7 \cdot 42\end{array}$ & $\begin{array}{l}0.76 \\
7.24\end{array}$ \\
\hline \multicolumn{3}{|c|}{$\begin{array}{l}\text { Systolic blood pressure } \\
\text { on admission }\end{array}$} \\
\hline$(\mathbf{m m H g})$ & 72 & 64 \\
\hline Mechanical ventilation & 0 & 3 \\
\hline $\begin{array}{l}\text { Duration of oxygen } \\
\text { therapy (hours) }\end{array}$ & 46 & 98 \\
\hline Survival & 19 & 6 \\
\hline
\end{tabular}




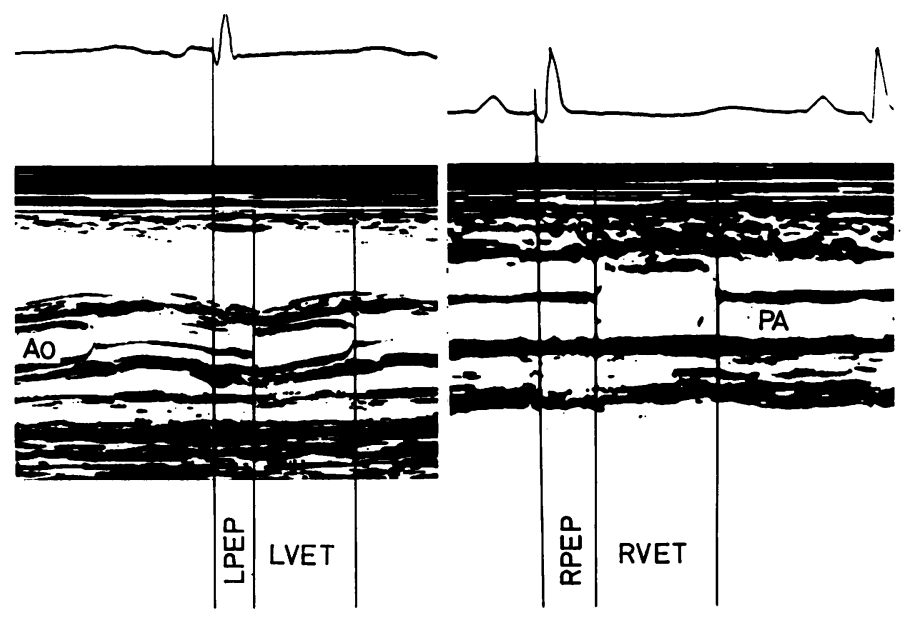

Fig. 1 Echograms of aorta (Ao) and pulmonary artery $(P A)$ recorded at $100 \mathrm{~mm} /$ second from a 56-hour-old infant with severe TTN. LPEP is the left ventricular pre-ejection period from $Q$-wave on ECG to aortic valve opening (75 milliseconds). LVET is the left ventricular ejection time from valve opening to closure (180 milliseconds). $R P E P$ and $R V E T$ are the right ventricular systolic time intervals measured from the pulmonary valve echogram (100 and 200 milliseconds respectively). LPEP/LVET ratio is $75 / 180=0.42, R P E P / R V E T$ ratio is $100 / 220=0.45$. Normal value for each ratio is about 0.35 (see Fig. 2).

least twice, and a total of 55 echocardiograms was obtained.

A second group of 6 infants with a much more severe clinical course was also studied. The classical clinical and radiographic signs of TTN were present but these infants required much more oxygen $(>60 \%)$, in order to maintain normal arterial oxygen tensions. They also suffered from appreciably more asphyxia and acidosis in the perinatal period (Table). In this group the duration of treatment with oxygen was much greater and we have designated such babies as having severe TTN. These infants were also studied echocardiographically on at least two separate occasions.

The echocardiographs were used to measure ventricular systolic time intervals as previously described. ${ }^{6} 7$ The ultrasonoscope (Organon Teknika Echomatic) was used to record aortic and pulmonary valve echograms at paper speeds of $100 \mathrm{~mm} / \mathrm{second}$ (Fig. 1). Left ventricular pre-ejection period (LPEP) was measured from the onset of the QRS complex on the electrocardiogram to the point of aortic valve opening, and left ventricular ejection time (LVET) was measured from opening to closure of the aortic valve. In a similar fashion RPEP and RVET were measured from the pulmonary valve echogram.

\section{Results}

Group 1, babies with mild classical TTN, had a mean gestational age of 37 weeks and a mean birthweight of $2.7 \mathrm{~kg}$. In this group the LPEP/LVET ratio was appreciably greater than that of controls during the first 24 hours of life (Fig. 2). The initial LPEP/LVET ratio of each infant correlated with the length of

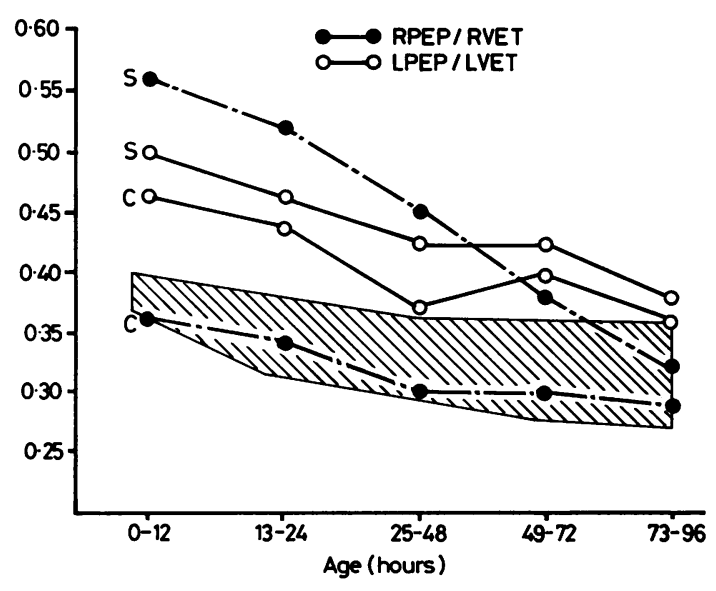

Fig. 2 Mean RPEP/RVET and LPEP/LVET ratios plotted against age in hours for the 19 infants with classical TTN $(C)$ and the 6 infants with severe TTN $(S)$. The normal range (mean $\pm S D$ ) is hatched. ${ }^{11} 12$

time treatment with oxygen was required (Fig. 3). The RPEP/RVET ratios were not increased at any time in these babies with classical TTN.

Group 2, babies with severe TTN, had a mean gestational age of 39 weeks and a mean birthweight of $3.26 \mathrm{~kg}$. With the exception of one, all were term. The LPEP/LVET ratio was significantly greater than for normal controls for the first 3 days of life and the RPEP/RVET ratio was also increased (Figs 1 and 2). In this group the duration of oxygen treatment was unrelated to the initial LPEP/LVET ratio and correlated only poorly with the initial RPEP/RVET ratio. 


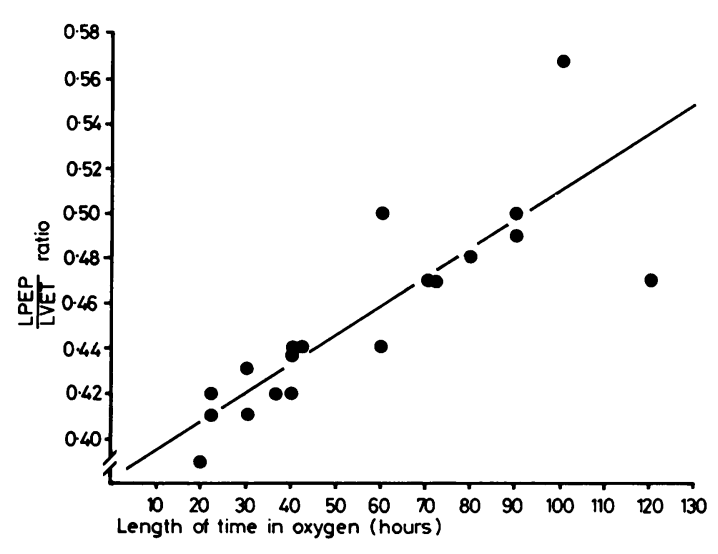

Fig. 3 Initial LPEP/LVET ratios from the infants with classical TTN plotted on the vertical axis against period of oxygen treatment in hours. The relationship is described by the formula: LPEP/LVET $=0.0012$ (hours in $\left.\mathrm{O}_{2}\right)+0.39(\mathrm{r}=0.82) . \mathrm{LPEP}=$ left ventricular pre-ejection period and $L V E T=$ left ventricular ejection time.

Babies in both groups had normal haematocrits and blood pressures, and similar fluid intakes during the first day (Table). Three of the 6 babies with severe TTN needed mechanical ventilation for hypoxaemia but all babies survived.

\section{Discussion}

TTN was first described by Avery et al. in $1966 .{ }^{1}$ The aetiology is uncertain but delayed resorption of lung fluid has been widely accepted as the underlying problem. ${ }^{18}$ Association of TTN with perinatal asphyxia, maternal over-sedation, and hypothermia has been noted.$^{39}$ Asphyxia will favour the development of lung oedema by direct action on the pulmonary capillary ${ }^{8}$ but it may also have a direct depressive action on myocardial function.

Myocardial contractility may be non-invasively assessed using echocardiography, and the measurement of left ventricular systolic time intervals has been used for some time as an index of myocardial contractility. ${ }^{10}$ The pre-ejection period to ejection time ratio (LPEP/LVET) in the newborn period is normally 0.35 and values greater than 0.40 suggest left ventricular failure. ${ }^{11} 12$ Similarly the echocardiogram may be used to measure right ventricular systolic time intervals (RPEP and RVET) and the ratio of RPEP to RVET reflects pulmonary artery pressure and pulmonary vascular resistance. ${ }^{13}$ Normal RPEP/RVET ratio in the newborn declines with postnatal age but after 12 hours values over
0.40 are generally taken as indicating increased pulmonary vascular resistance or right ventricular dysfunction. ${ }^{11} 12$

In group 1 infants with classical TTN, there was echographic evidence of disordered left ventricular contractility in the first 24 hours of life. These infants had no echographic evidence of right ventricular dysfunction nor had they increased pulmonary vascular resistance and the clinical course was both mild and short so that one might conclude that their transient tachypnoea was due to transient left ventricular failure. However, in none of these babies had there been excessive use of intravenous fluids, blood transfusions, or hyperosomolar infusion. Equally there was no evidence of polycythaemia as assessed by measurement of the haematocrit.

The 6 infants with severe disease showed abnormalities of systolic time intervals of both ventricles. These abnormalities persisted for much longer (up to 72 hours) than in classical TTN. The findings suggest that severe TTN may be due to generalised myocardial failure affecting both left and right ventricles. Alternatively, the increase in LPEP/LVET ratio may be due to mild left ventricular failure as in classical TTN while the increase in RPEP/RVET ratio may be due to an increase in pulmonary vascular resistance or pulmonary hypertension in these infants. This increase in pulmonary vascular resistance may be caused by perinatal asphyxia and acidosis, or by acute over-inflation of the lungs resulting in pulmonary capillary compression. ${ }^{4}$ In this respect these infants resemble those with persistent fetal circulation and have similar echographic findings. ${ }^{14}$ We believe that our babies did indeed have pulmonary hypertension but unfortunately we did not confirm the presence of right-to-left shunting by differential blood gas sampling on each side of the ductus arteriosus. It is of importance that each baby had radiographic changes of TTN that were indistinguishable from those with the milder illness.

We suggest that there are two distinct types of TTN: one benign and one severe. The benign or classical type may result from mild transient left ventricular failure, perhaps as a result of mild birth asphyxia or circulatory overload. The severe type often follows more obvious asphyxia and is characterised by a prolonged illness with increased oxygen needs. In this type of TTN there may be more generalised myocardial failure and pulmonary hypertension with right-to-left shunting so that persistent fetal circulation syndrome may occur.

Echocardiography may be used to evaluate infants with respiratory disorders ${ }^{15}$ and will distinguish between these two forms of TTN. Infants 
with severe TTN should be cared for in neonatal intensive care units where close monitoring and mechanical ventilation are available.

We thank Mrs Lynda Thompson for typing the manuscript and $\mathrm{Mr}$ Ronnie Woods for photographing the echocardiograms.

\section{References}

1 Avery M E, Gatewood O B, Brumley G. Transient tachypnoea of newborn. Possible delayed resorption of fluid at birth. Am J Dis Child 1966; 111: 380-5.

2 Wesenberg R L, Graven S N, McCabe E B. Radiological findings in wet-lung disease. Radiology 1971; 98: 69-74.

3 Halliday H L, McClure B G. Transient tachypnoea of newborn. A review of 28 infants. Ulster Med J 1975; 44: 153-8.

4 Bucciarelli R L, Egan E A, Gessner I H, Eitzman D V. Persistence of fetal cardiopulmonary circulation: one manifestation of transient tachypnea of the newborn. Pediatrics 1976; 58: 192-7.

5 Tudehope D I, Smyth M H. Is 'transient tachypnoea of the newborn' always a benign disease? Report of 6 babies requiring mechanical ventilation. Aust Paediatr $J$ 1979; 15: $160-5$.

6 Hirschfeld S S, Meyer R A, Schwartz D C, Korfhagen J, Kaplan S. Measurement of right and left ventricular systolic time intervals by echocardiography. Circulation 1975; 51 : 304-9.

7 Halliday H L, Hirschfeld S S, Riggs T, Liebman J, Fanaroff A A, Bormuth C. Respiratory distress syndrome: echocardiographic assessment of cardiovascular function and pulmonary vascular resistance. Pediatrics 1977; 60: 444-9.
8 Taylor P M, Allen A C, Stinson D A. Benign unexplained respiratory distress of the newborn infant. Pediatr Clin North Am 1971; 18: 975-1004.

9 Sundell H, Garrott J, Blankenship W J, Shepard F M, Stahlman M T. Studies on infants with type II respiratory distress syndrome. J Pediatr 1971; 78: 754-64.

10 Weissler A M, Harris W S, Schoenfeld C D. Bedside technics for the evaluation of ventricular function in man Am J Cardiol 1969; 23: 577-83.

11 Riggs T, Hirschfeld S S, Bormuth C, Fanaroff A A, Liebman J. Neonatal circulatory changes: an echocardiographic study. Pediatrics 1977; 59: 338-44.

12 Halliday $H$ L, Hirschfeld S S, Riggs T, Liebman J, Fanaroff A A. Echocardiographic ventricular systolic time intervals in normal term and preterm neonates. Pediatrics 1978; 62: 317-21.

13 Hirschfeld S S, Meyer R A, Schwartz D C, Korfhagen J, Kaplan S. The echocardiographic assessment of pulmonary artery pressure and pulmonary vascular resistance. Circulation 1975; 52: 642-50.

14 Riggs T, Hirschfeld S S, Fanaroff A A, Liebman J, Fletcher B D, Meyer R A. Persistence of fetal circulation syndrome: an echocardiographic study. J Pediatr 1977; 91: 626-31.

15 Halliday H L. Measurement of ventricular systolic time intervals in the normal and ill newborn by $M$-mode echocardiography. In: Rolfe P, ed. Fetal and neonatal physiological measurements. London: Pitman Medical and Biological Engineering Society, 1980: 70-89.

Correspondence to Dr H L Halliday, The Queen's University of Belfast, Institute of Clinical Science, Grosvenor Road, Belfast BT12 6BJ.

Received 25 February 1980 